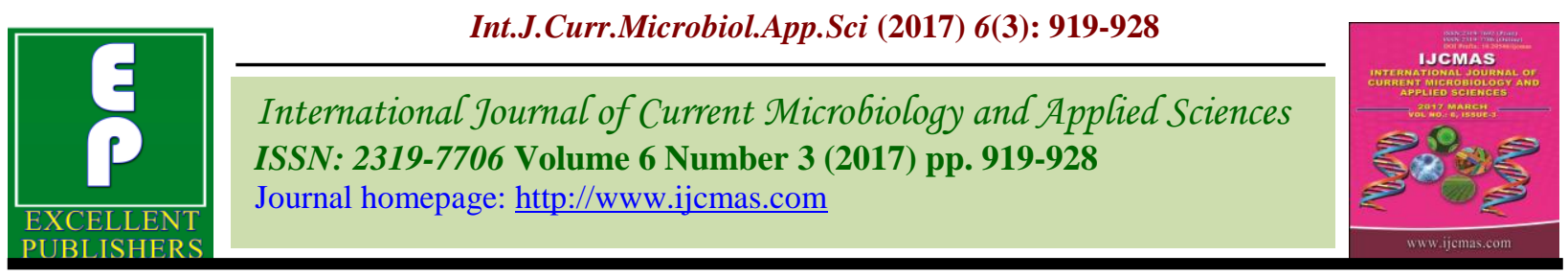

Original Research Article

https://doi.org/10.20546/ijcmas.2017.603.109

\title{
Isolation, Production and Optimization of Siderophores (Iron Chilators) from Pseudomonas fluorescence NCIM 5096 and Pseudomonas from Soil Rhizosphere and Marine Water
}

\author{
Jayashri Pattan ${ }^{1 *}$, Swapnil Kajale ${ }^{2}$ and Shashikant Pattan ${ }^{3}$ \\ ${ }^{1}$ Dr D.Y. Patil Arts, Commerce and Science College, Pimpri, Pune, India, 411018 \\ ${ }^{2}$ Microbial Culture Collection, National Centre for Cell science, Pune, India 411021 \\ ${ }^{3}$ Abasaheb Kakade Collage of B. Pharmacy, Bodhegaon, A'nagar, India \\ *Corresponding author
}

\section{A B S T R A C T}

\begin{tabular}{l}
\hline Ke y w o r d s \\
$\begin{array}{l}\text { Siderophores, } \\
\text { Phytopathogens, } \\
\text { Pseudomonas sp. }\end{array}$ \\
\hline Article Info \\
\hline $\begin{array}{l}\text { Accepted: } \\
\text { 18 February } 2017 \\
\text { Available Online: } \\
\text { 10 March } 2017\end{array}$ \\
\hline
\end{tabular}

Two Pseudomonas spp. are isolated from different natural sources i.e. soil rhizosphere and marine water on selective media like cetrimide agar base and King's B medium. Pseudomonas fluorescence NCIM 5096 and other two isolated of Pseudomonas produced siderophore with the yield $71 \%, 72.33 \%, 33 \%$ of hydroxamate type, in iron free succinate medium (SM). Nutrient medium inhibited the growth of siderophore while the succinate medium gave the maximum production of siderophore. $\mathrm{pH}$ has important role in production of siderophore i.e. at neutral $\mathrm{pH}$ 7; maximum siderophore yield while at acidic $\mathrm{pH}$ production was found ceasing. Succinate medium supplemented with $\mathrm{Pb}$ showed enhancement while other supplemented with Co showed inhibition of production of siderophore. Isolated siderophore showed the antagonists effects against human pathogenic Pseudomonas aeruginosa and on phytopathogenic fungi.

\section{Introduction}

The role of siderophores is to scavenge iron from the environment and to make the mineral, which is almost always essential, available to the microbial cell. Important groups of siderophores include hydroxamate siderophores, catecholate (phenolates) siderophores and carboxylate siderophores. In Open Ocean, the iron content is low because of its solubility nature in sea water. When iron is scarce, marine bacteria (and possibly some kinds of microalgae) make siderophores. Siderophores are chemically diverse and feature either catecholate, hydroxamic acid or citric acid based Fe (III) binding groups. Proteins located at the bacterial cell surface or outer membrane recognize the soluble Fe(III)- siderophore complex with high specificity and actively transport the complex into the cell with the Fe ultimately released in the cytoplasm. Siderophore producing Pseudomonas sp. Play vital role in stimulating plant growth and in controlling several plant diseases. They function as a biocontrol agent by depriving the pathogen like phytopathogens from iron nutrition. A different strain, Pseudomonas fluorescence NCIM 5096 produces an iron binding fluorescent pigment, studied by Chincholkar et al., (2004) who found it as most promising group of plant growth promoting rhizobacteria (PGPR) involved in plant growth promotion and disease control. Our 
work began as an effort to isolate Pseudomonas from soil rhizosphere and marine water and their identification. In this study it was demonstrated that siderophore production varies with different conditions provided; also antagonistic effects on pathogenic Pseudomonas aeruginosa and phytopathogenic fungi. Hence the present study carried out UV visible Spectrophotometric and Fourier transform infrared spectrometric characterization of produced siderophores.

\section{Materials and Methods}

\section{Source and isolation}

Pseudomonas fluorescence NCIM 5096 was obtained from National Chemical Laboratory (NCL), Pune, India. Pseudomonas was isolated from soil rhizosphere by serial dilution method on selective medium like Kings agar B, Cetrimide agar base and Dettol agar (Hi-Media). Another Pseudomonas was isolated from marine water sample from Juhu beach, Mumbai on marine nutrient agar. Pathogenic Pseudomonas aeruginosa was collected from Pravara Medical Trust (PMT), Pravaranagar.

\section{Identification and maintenance}

The identification of isolated bacteria was done at PDPVVP's Medical College, Ahmednagar. All the four strains were maintained at $4^{0} \mathrm{C}$ on nutrient agar and were used in further studies.

\section{Inoculum development}

Loopful culture of $P$. fluorescence 5096 and both isolated Pseudomonas from nutrient agar were separately inoculated in $250 \mathrm{ml}$ of iron deficient Succinate medium (SM) and incubated at $24-30^{\circ} \mathrm{C}$ for $48 \mathrm{hrs}$ with constant shaking at $100 \mathrm{rpm}$.
Production of siderophore, U.V. Spectrophotometric analysis and \% siderophore unit

For production of siderophore Pseudomonas iron deficient SM was used which consists of g L ${ }^{-1}: \mathrm{K}_{2} \mathrm{HPO}_{4}, 6.0 ; \mathrm{KH}_{2} \mathrm{PO}_{4}, 3.0 ; \mathrm{MgSO}_{4}$ $7 \mathrm{H}_{2} \mathrm{O}, 0.2 ;\left(\mathrm{NH}_{4}\right)_{2} \mathrm{SO}_{4}, 1.0$ and Succinic acid 4.0, pH 6.8 - 7. 24-30 h old cultures of Pseudomonas fluorescence NCIM 5096 and other two isolated Pseudomonas were inoculated and incubated for $24-30 \mathrm{~h}$ at $28^{\circ} \mathrm{C}$ with constant shaking at $100 \mathrm{rpm}$. After incubation period cultures were centrifuged separately at $10000 \mathrm{rpm}$ for $15 \mathrm{~min}$ and cell free supernatant was subjected for U.V. Spectrophotometric analysis and estimation of siderophore.

UV Spectrophotometric analysis was done by using CAS reagent in equal volume with cell free supernatant at $200-800 \mathrm{~nm}$ range.

Percent siderophore unit was calculated by CAS shuttle assay in which $0.8 \mathrm{ml}$ of CAS reagent was mixed with $0.8 \mathrm{ml}$ of cell free supernatant giving orange color and absorbance was measured at $630 \mathrm{~nm}$ against reference consisting of $0.8 \mathrm{ml}$ of uninoculated broth/ millipore water with equal volume of CAS reagent.

Siderophore content in aliquot was calculated by using following formula;

$$
\% \text { siderophore unit }=\frac{\mathrm{Ar}-\mathrm{As}}{\mathrm{Ar}} \times 100
$$

Where, $\mathrm{Ar}=$ absorbance of reference at 630 nm (CAS reagent)

As $=$ absorbance of sample at $630 \mathrm{~nm}$.

\section{Siderophore production on different media}

Two different media were used like

Nutrient broth consists of $\mathrm{g} \mathrm{L}^{-1}$ : Peptone, 10.0; Beef extract, $5 \mathrm{gm} ; \mathrm{NaCl}, 10.0 ; \mathrm{pH}, 7.2$ $\pm 0.5$ 
Succinate media (SM) consists of $\mathrm{g} \mathrm{L}^{-1}$ : $\mathrm{K}_{2} \mathrm{HPO}_{4}, 6.0 ; \mathrm{KH}_{2} \mathrm{PO}_{4}, 3.0 ; \mathrm{MgSO}_{4} 7 \mathrm{H}_{2} \mathrm{O}$, $0.2 ;\left(\mathrm{NH}_{4}\right) 2 \mathrm{SO}_{4}, 1.0$ Succinic acid 4.0, $\mathrm{pH} 6.8$ -7 .

All three species were inoculated in both media and incubated at RT for 48 hrs. After incubation U.V. spectra was taken and siderophore content was quantified by formula.

\section{Optimization of cultural conditions}

\section{Influence of pH on growth of siderophore}

Iron free SM was prepared each with two different $\mathrm{pH}$ as 4.5 and 7. Each of three flasks was incubated separately by three samples to check the effect on growth and siderophore production.

\section{Influence of heavy metals}

All the three cultures were separately grown in SM. Each of $50 \mathrm{ml} \mathrm{SM}$ was separately supplemented with $10 \mu \mathrm{M}$ of cobalt chloride $\left(\mathrm{CoCl}_{2}\right)$ and lead acetate $\left(\mathrm{PbCH}_{3} \mathrm{CHOO}\right)$. Following the incubation at $28^{0} \mathrm{C}$ with constant shaking at 100rpm growth and siderophore production was estimated out.

\section{Extraction and FTIR analysis}

After centrifugation the cell free supernatant of each sample was mixed with equal volume of ethyl acetate separately (1:1) in separating funnel. After $24 \mathrm{~h}$ organic phase was separated in another sterile iron free bumper tube and stored at $4^{0} \mathrm{C}$. FTIR analysis of extracted samples was carried at KTHM College, Nashik.

Effect of siderophore on growth of pathogenic Pseudomonas aeruginosa and phytopathogenic fungi

\section{Antibacterial assay}

Mueller- Hinton agar (MHA) consisting of $\mathrm{g}$
$\mathrm{L}^{-1}$ : Beef infusion solids, 4.0; Starch, 1.5; Casein hydrolysate, 17.5; Agar, 15.0; pH, 7.2 -7.4 was prepared by spread plate technique for growth of pathogenic Pseudomonas aeruginosa. Sterile Whatmann's paper discs were dipped into three supernatant separately for half an hour. Three discs from samples were placed at 3 different opposite places on solidified MHA plate on which pathogenic Pseudomonas aeruginosa was already spread. Plates were incubated at $37^{\circ} \mathrm{C}$ for $24 \mathrm{~h}$ and zone of inhibition was observed.

\section{Phytopathogenic assay}

Potato-Dextrose agar (PDA) consists of $\mathrm{g} \mathrm{L}^{-1}$ : Potato, 200.0; Dextrose, 20.0; Agar, 15.0 was prepared and distributed in 5 flasks. Autoclaved medium when slightly cooled spores of different fungi such as Aspergillus flavus, Monila, Humicola, Aspergillus niger, Periconia, Geophila, Candida albicans were added in different flasks. The media was poured in Petri dishes. Sterile Whatmann's paper discs were dipped into three supernatant separately for half an hour. Three discs from samples were placed at 3 different opposite places on solidified media. Plates were incubated at room temperature for $48 \mathrm{~h}$. Zone of inhibition was observed and diameter was calculated.

\section{Results and Discussion}

\section{Isolation and identification of Pseudomonas from soil and marine water}

Work had started with the intention to isolate Pseudomonas from rhizosphere soil and marine water. First, serial dilution (10 $\left.{ }^{4}\right)$ suspension was streaked on the king's B medium. After $24 \mathrm{hr}$ it has shown the crowded colonies. These were then purified on to Cetrimide agar plate. Colony characteristics were noted down, further identification was carried out at PDVVPF'S medical college, Ahmednagar. As the bacteria 
were Gram negative rods with semitransparent in appearance. With the help of biochemical tests it was confirmed that organisms were Pseudomonas spp.

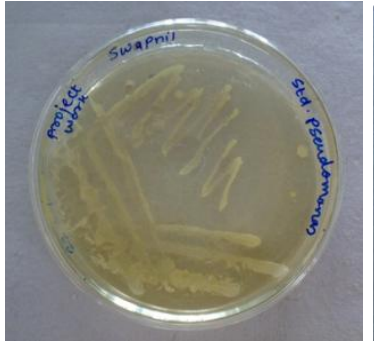

a)

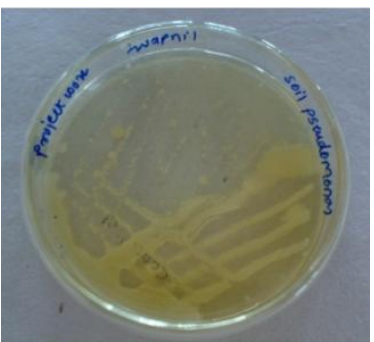

b)

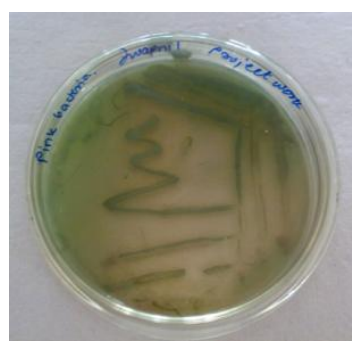

c)

a) Pseudomonas fluorescence NCIM 5096 b) Pseudomonas spp from soil rhizosphere c) Pseudomonas aerugenosa from marine water

\section{Production \% spectrophotometric detection and estimation of siderophore}

After 24-36 hr of incubation, development of green coloured pigment in SM by marine Pseudomonas and also $\mathrm{pH}$ changed to 9 in all three broths indicated the production of siderophore. This was further confirmed by qualitative CAS test where instant decolorization of CAS reagent from blue to orange red was observed with three cultures. All three cultures produced $71 \%, 72.33 \%$, $33 \%$ units of siderophores (hydroxamate type) in SM, respectively.

\section{Optimization parameters}

\section{Influence of media}

While studying influence of media preparation, it was found that development of green colour and $\mathrm{pH}$ change was only observed in SM and not in nutrient broth. As there was no colour change in nutrient broth indicating the absence of siderophore production in the medium. Pseudomonas fluorescence NCIM 5096, sample 1 (Pseudomonas spp), sample 2 (Pseudomonas aeruginosa) gave maximum siderophore unit in SM than in nutrient media (Table 1). This indicated that $\mathrm{SM}$ is most suitable for siderophore production from all 3 Pseudomonas sps.

\section{$\mathbf{p}^{\mathrm{H}}$ of medium}

$\mathrm{pH}$ plays important role in the solubility of iron and thereby its availability to the growing organism in the medium. For the two $\mathrm{pH}$ values (Table 1) it was evident that at neutral $\mathrm{pH}$ (7), maximum siderophore yield (71\%, $72.33 \%, 33 \%$ ) was obtained which may be because bacteria grow better and iron was present in insoluble form at neutral $\mathrm{pH}$ and therefore was not available to the bacteria. This stress of iron induces siderophore production. With increase in acidity siderophore production was found ceasing.

\section{Influence of heavy metals}

In case of heavy metals it was observed that the medium supplemented with $\mathrm{Pb}$ in the form of lead acetate enhanced the siderophore production as well as growth of culture while media supplemented with Co show reduced production and growth (Table 1) of Pseudomonas fluorescence NCIM 5096 and soil Pseudomonas isolate. Marine water isolate did not show Co inhibitory effect. Maximum siderophore production was detected by Marine Pseudomonas isolate $(84.66 \%)$

\section{FTIR}

FTIR is more sensitive; the optical throughput 
is much higher which results in much lower noise levels. By carrying out FTIR of three samples we observed that all the three samples were having common functional groups (Table 2) present which were; $\mathrm{N}-\mathrm{H}$ (Amines), $-\mathrm{OH}$ alcohol $\mathrm{C}-\mathrm{O}$ stretch, $\mathrm{C}=\mathrm{O}$ stretch. These groups are present in the siderophore structures. Hence by combining the total effect of U.V. spectrophotometer and FTIR analysis the presence of siderophore in sample was confirmed.

FTIR analysis: FTIR of standard sample

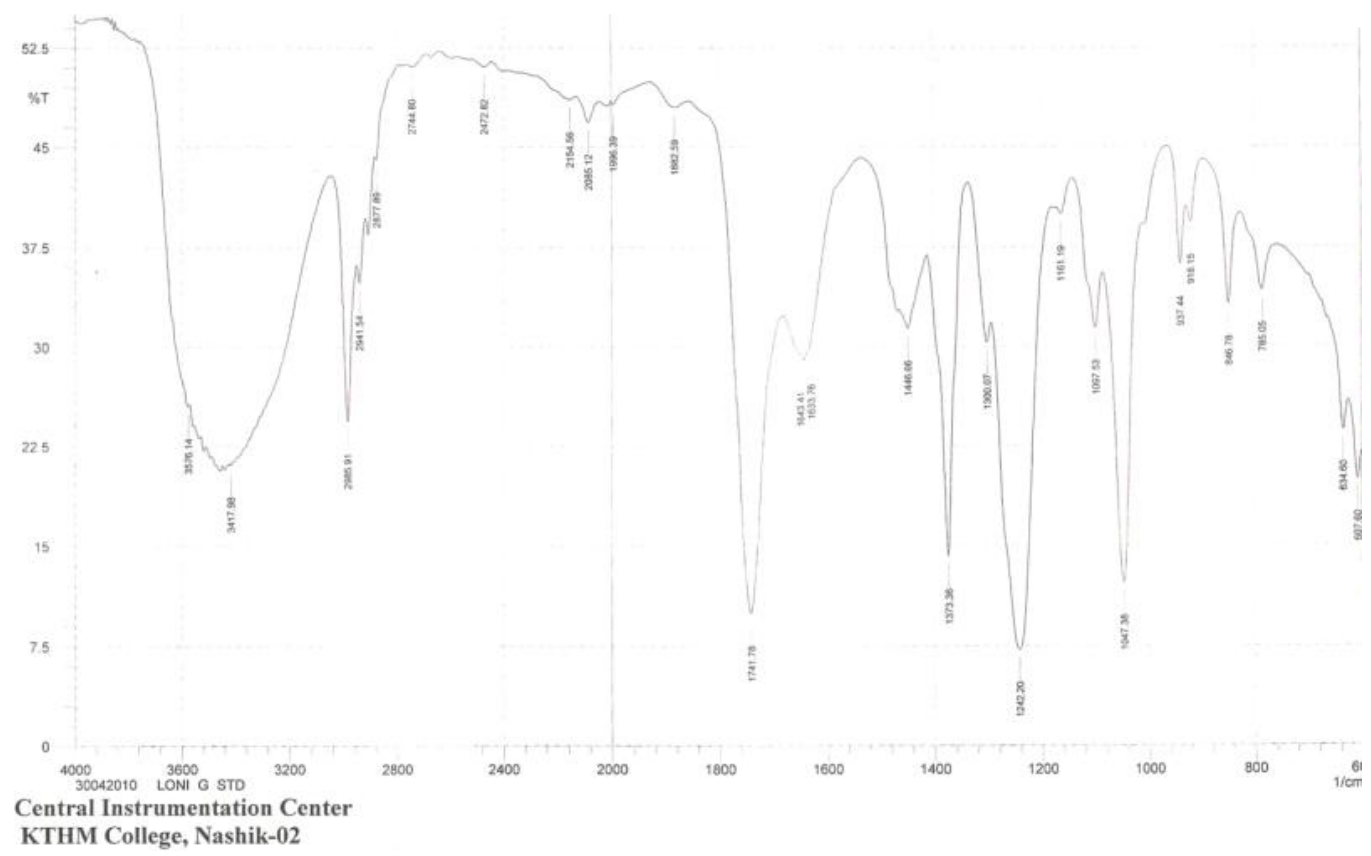

FTIR of standard extracted sample

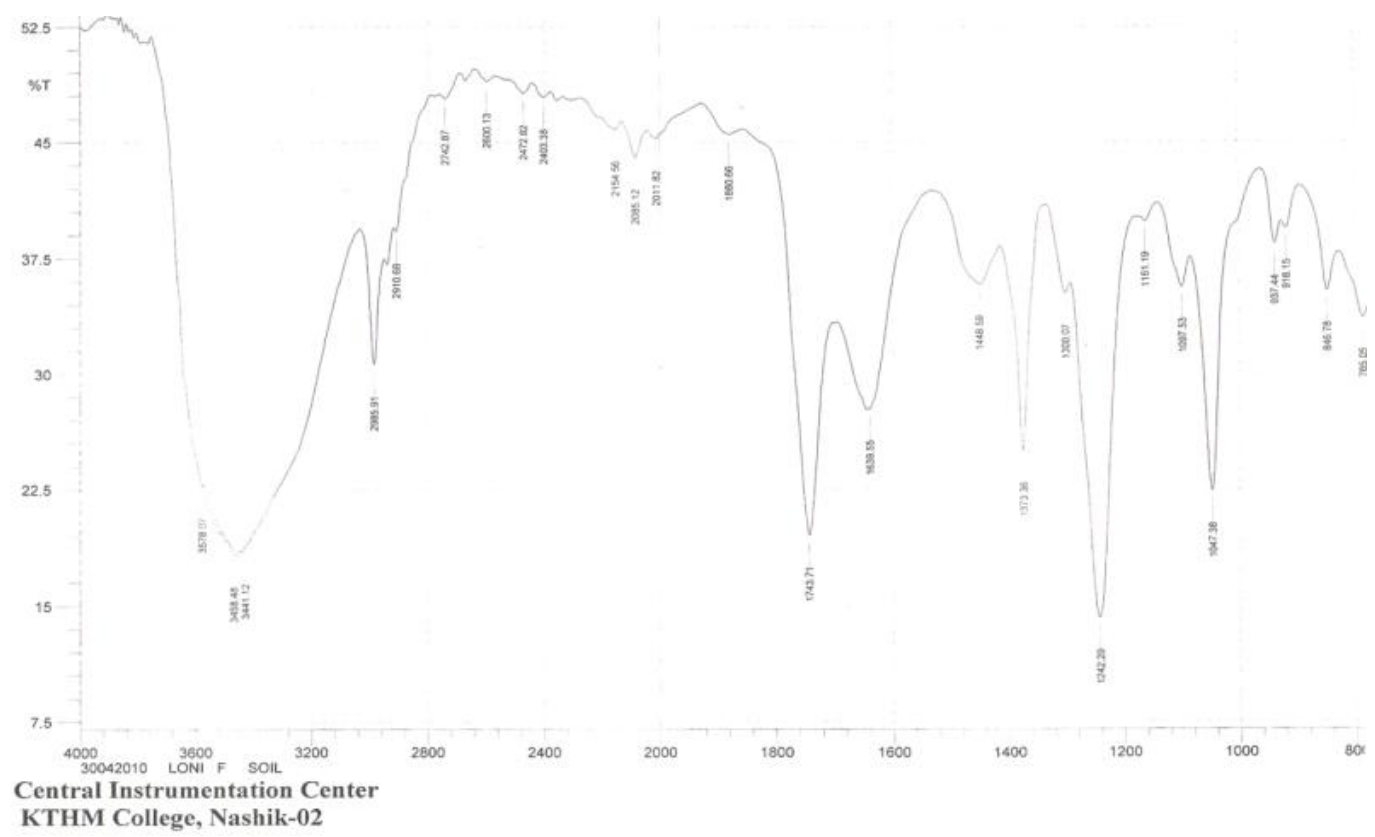




\section{FTIR of extracted sample 1}

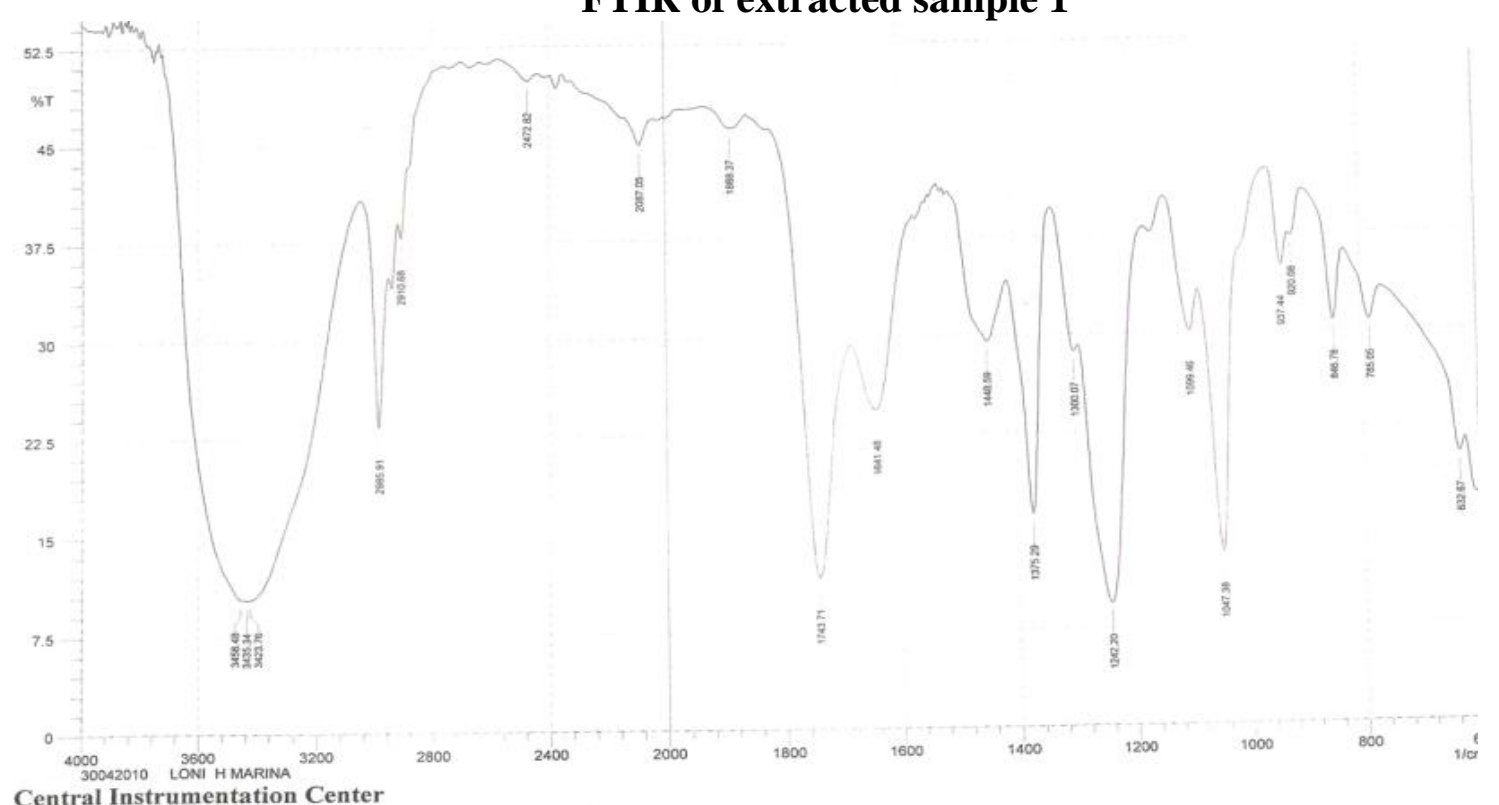

FTIR of extracted sample 2

Pseudomonas fluorescence NCIM 5096 showed $\lambda$ max at 252 (Pyochelin), 401, 407 (Pyoverdin) and 359 (Phenazine). Soil Pseudomonas sp showed $\lambda \max$ at 275 (Catechole), 360 (Phenanzin) and 401(Pyoverdin)

Marine Pseudomonas sp- showed $\lambda$ max at 247 (Catechole), 401, 405, 407, 406 (Pyoverdin), 366 (Phenanzine pigment) and 386, 391.387, 396 (Hydroxymate)

\section{Phytopathogenic activity}

In case of both assays it was proved that siderophores were acted as an antagonist against pathogenic Pseudomonas aeruginosa and phytopathogenic fungi. The zone of inhibition (Table 3) was more in case of Aspergillus niger indicates that siderophore can be used as a biocontrol agent.

\section{Antifungal}

Siderophore's antibacterial activity was tested against pathogenic Pseudomonas collected from Pravara Medical college. Zone of inhibition $(\mathrm{A}=1.4 \mathrm{~cm}, \mathrm{~B}=1.33 \mathrm{~cm}, \mathrm{C}=1.4$ $\mathrm{cm})$ on MHA agar

* A= Standadrd sample Pseudomonas fluorescence NCIM 5096

* $\mathrm{B}=$ Pseudomonas $\mathrm{spp}$ (Soil sample)

* $\mathrm{C}=$ Pseudomonas aerugenosa (Marine water).

In conclusion, all three Pseudomonas cultures produced $71 \%, 72.33 \%, 33 \%$ units of siderophores (hydroxamate type) in SM, respectively. Lead in the form of lead acetate enhanced the siderophore production as well as growth of culture while media supplemented with $\mathrm{CO}$ show reduced production growth except Marine isolate. Pseudomonas from marine water showed better antifungal activity against Aspergillus flaus, Aspergillus niger, Periconia and Candida albicans while as Pseudomonas from soil showed better activity against Aspergillus flavus, Geophila and Candida albicans than standard strain. 
Table.1 Optimization of Siderophore production

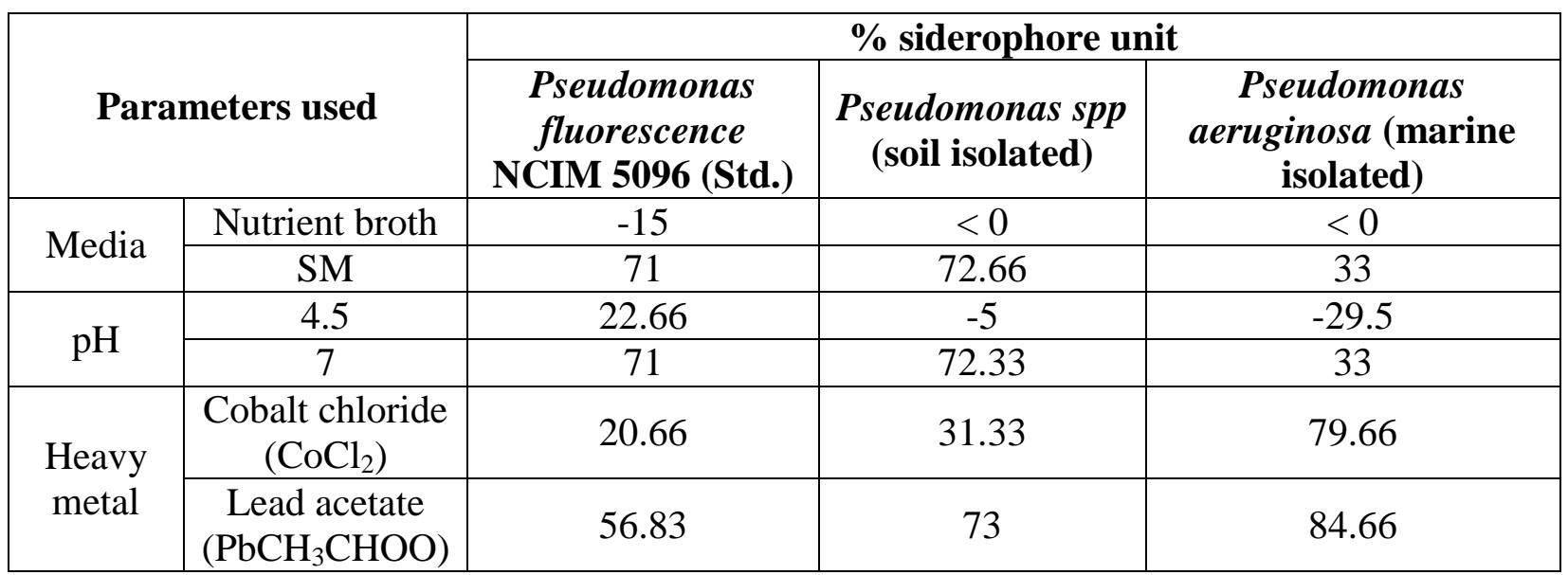

Table.2 Peaks and respective groups observed by FTIR analysis

\begin{tabular}{|c|c|c|}
\hline Sample & Peak & Group \\
\hline \multirow{11}{*}{$\begin{array}{l}\text { Standard sample } \\
\text { Pseudomonas } \\
\text { fluorescence NCIM } \\
5096\end{array}$} & 3576.14 & $\mathrm{~N}-\mathrm{H}$ \\
\hline & 3417.98 & $\mathrm{~N}-\mathrm{H} /-\mathrm{OH}$ \\
\hline & 2985.91 & -OH(carboxylic acid) \\
\hline & 2941.54 & C-H stretching \\
\hline & 1741.78 & $\mathrm{C}=\mathrm{O}$ stretching \\
\hline & $1643.41,1633.76$ & $\mathrm{C}=\mathrm{O}$ stretching \\
\hline & 1446.66 & $\mathrm{C}=\mathrm{O}$ stretching \\
\hline & 1373.36 & Alkyl C-H stretching \\
\hline & 1300.07 & C-O stretch \\
\hline & 1242.20 & C-O stretch \\
\hline & 1047.38 & C-O stretch \\
\hline \multirow{10}{*}{$\begin{array}{l}\text { Soil sample } \\
\text { Pseudomonas spp }\end{array}$} & 3578.07 & -OH (alcohol) \\
\hline & 3458.48 & $\mathrm{~N}-\mathrm{H}$ (Amines) \\
\hline & 3441.12 & N-H(Amines) \\
\hline & 2985.91 & -OH(carboxylic acid) \\
\hline & 2910.68 & -OH(carboxylic acid) \\
\hline & 1743.71 & $\mathrm{C}=\mathrm{O}$ stretch/ester \\
\hline & 1639.55 & $\begin{array}{ll}\text { Amids/ } & \mathrm{C}=\mathrm{O} \\
\text { stretching }\end{array}$ \\
\hline & 1373.36 & Alkyl C-H stretching \\
\hline & 1242.20 & $\mathrm{C}=\mathrm{O}$ stretching \\
\hline & 1047.38 & $\mathrm{C}-\mathrm{O}$ stretch \\
\hline \multirow{3}{*}{$\begin{array}{ll}\text { Marine } & \text { sample } \\
\text { Pseudomonas } \\
\text { aerugenosa }\end{array}$} & 3458.48 & $\begin{array}{ll}\text { N-H(Amines)/ } & \text {-oh } \\
\text { alcohol }\end{array}$ \\
\hline & 3435.34 & $\begin{array}{l}\text { N-H(Amines)/ -oh } \\
\text { alcohol }\end{array}$ \\
\hline & 3423.76 & $\mathrm{~N}-\mathrm{H}$ (Amines)/ \\
\hline
\end{tabular}




\begin{tabular}{|l|l|l|}
\hline & & alcohol \\
\cline { 2 - 3 } & 2985.91 & -OH(carboxylic acid) \\
\cline { 2 - 3 } 2910.68 & -OH(carboxylic acid) \\
\cline { 2 - 3 } & 1743.71 & C=O stretch \\
\cline { 2 - 3 } & 1641.48 & $\begin{array}{l}\text { Amids/ } \\
\text { stretching } \quad \mathrm{C}=\mathrm{O}\end{array}$ \\
\cline { 2 - 3 } & 1375.29 & $\mathrm{C}=\mathrm{O}$ stretch \\
\cline { 2 - 3 } & 1242.20 & $\mathrm{C}=\mathrm{O}$ stretch \\
\cline { 2 - 3 } & 1047.38 & C-O stretch \\
\hline
\end{tabular}

Table.3 Antifungal activity of siderophgore on phytopathogens

\begin{tabular}{|l|l|l|l|l|}
\hline \multirow{2}{*}{$\begin{array}{l}\text { Sr. } \\
\text { No. }\end{array}$} & Name of fungus & \multicolumn{3}{|l|}{ Zone of inhibition $(\mathrm{cm})$} \\
\cline { 3 - 5 } & & A & B & C \\
\hline 1 & Aspergillus flavus & 0.73 & $\mathbf{2 . 1}$ & $\mathbf{2}$ \\
\hline 2 & Monila & 0.6 & 0.63 & 0.7 \\
\hline 3 & Humicola & 2.2 & 1.3 & 1.46 \\
\hline 4 & Aspergillus niger & 2.6 & 1.83 & $\mathbf{3 . 5 3}$ \\
\hline 5 & Periconia & 2.36 & 2.26 & $\mathbf{2 . 5 3}$ \\
\hline 6 & Geophila & 0.7 & $\mathbf{1 . 7 3}$ & 1 \\
\hline 8 & Candida albicans & 1.7 & $\mathbf{3 . 1}$ & $\mathbf{3 . 1 3}$ \\
\hline
\end{tabular}

The zone of inhibition is more in case of Aspergillus niger indicates that siderophore can be used as a biocontrol agent. We could isolate different types of siderphores from Standard Pseudomonas strains, soil Pseudomonas isolate and marine Pseudomonas as observed by Alison Butlerand et al., at from Oceanography, have isolated and characterized several siderophores from marine microorganisms. These siderophores are structurally quite different from known terrestrial siderophores.

In Martha Páez et al., (2005) showed that siderophore producing Pseudomonas acts as antagonists against pathogenic rhisoctonia solani and botrytis cinerea. Dr Rachel Codd from Bosch Institute (Pharmacology) had worked on the siderophore. They have studied bacterial metal-management strategies which have implications for treating iron overload disease and for better understanding bacterial pathogenic virulence

In this experiments siderophores showed Pyochelin, Pyyoverdin, Phenazine, Catechol and Hydroxymate groups. Soil isolate and Pseudomonas fluorescence NCIM 5096 Sokol, et al - Azurechelin was distinct from the other siderophores of $P$. cepacia, having absorbance maxima at 210,250 and $310 \mathrm{~nm}$, whereas those of pyochelin are at 240 and 310 $\mathrm{nm}$ and those of cepabactin are reported to be 330 and $440 \mathrm{~nm}$.

The zone of inhibition is more in case of Aspergillus niger indicates that siderophore can be used as a biocontrol agent.

\section{Acknowledgement}


We are, Department of Biotechnology, P.V.P. College of arts, Commerce and science, Pravaranagar, Ahmednagar-413713 India for giving us opportunity to conduct this work. We would like to place on record our sincere thanks to Dr. S.B. Chincholkar and Meghraj Kadam, North Maharashtra University, Jalgaon for their cooperation in work. We are also thankful to Microbiology Department, Pravara Medical Trust, Pravaranagar for providing the necessary pathogenic bacterial strains.

\section{References}

Ankenbauer Robert, Somporn Sriyosachati, And Charles D. Cox. 1985. Effects of siderophores on the growth of Pseudomonas aeruginosa in human serum and transferrin. Infection and Immunity. American Society for Microbiol., 49: 132-140.

Britigan Bradley E., George T. Rasmussen, And Charles D. Cox. 1996. Augmentation of oxidant injury to human pulmonary epithelial cells by the Pseudomonas aeruginosa siderophore pyochelin. Infection and Immunity. American Society for Microbiol., 65: 1071-1076.

Britigan Bradley, E., George, T., Rasmussen, Oyebode Olakanmi and Charles, D., Cox. 1999. Iron acquisition from Pseudomonas aeruginosa siderophores by human phagocytes: an additional mechanism of host defense through iron sequestration. Infection and Immunity. American Society for Microbiol., 68: 1271-1275.

Budzikiewicz Herbert. 2001. SiderophoreAntibiotic conjugates used as Trojan horses against Pseudomonas aeruginosa. Curr. Topics in Med. Chem., 1: 73-82.

Cody Yvonne, S. and Dennis, C., Gross. 1987. Characterization of Pyoverdinp S5, the fluorescent siderophore produced by Pseudomonas syringae pv. Syringae. Appl. Environ. Microbiol., 53: 928-934.

Duffy Brion, K. and Genevie'Ve De'Fago. 1999. Environmental factors modulating antibiotic and siderophore biosynthesis by Pseudomonas fluorescens biocontrol strains. Appl. Environ. Microbiol., 65: 2429-2438.

Dubay, R.C. and D.K. Maheshwary. 2006. Practical microbiology, S. Chand and company ltd. 213-215.

Jones Lois Faye, J.P., Zakanycz, Evan, T., Thomas, and J.J. Farmer III. 1973. Pyocin typing of Pseudomonas aeruginosa: A simplified method. Appl. Microbiol., 27: 400-406.

Loeper Joyce, E. 1988. Role of fluorescent siderophore production in biological control of Pythium ultimum by a Pseudomonas fluorescence strain. Phytopathol., 78: 166-172.

Meyer J.M. And M.A. Abdallah. 1978. The Fluorescent pigment of Pseudomonas fluorescens: Biosynthesis, purification and physicochemical properties. $J$. General Microbiol., 107: 319-328.

Meyer Jean-Marie and Mohamed A. Abdallah. 1979. The Siderochromes of Non-fluorescent Pseudomonads: Production of Nocardamine by Pseudomonas stutzeri. J. General Microbiol., 118: 125-129.

Mossialos Dimitris, Jean-Marie Meyer, Herbert Budzikiewicz, Ulrich Wolff, Nico Koedam, Christine Baysse, Vanamala Anjaiah, And Pierre Cornelis. 1999. Quinolobactin, a new siderophore of Pseudomonas fluorescens ATCC 17400, the production of which is repressed by the cognate pyoverdine. Appl. Environ. Microbiol., 66: 487-492.

Philson, S., Stephen, B. and Miguel Llina. 1981. Siderochromes from Pseudomonas fluorescens I. Isolation 
and Characterization. J. Biol. Chem., 257: 8081-8085.

Philsons Stephen, B., and Miguel Llina. 1981.

Siderochromes from Pseudomonas

fzuorescens II. Structural homology as revealed by NMR spectroscopy. $J$. Biol. Chem., 257: 8086-8090.

Pelczar Michael, J., E.C.S. Chan. 1993. Microbiology. Tata Mac Graw Hill, Fifth edition, 267-268, 545-550.

Sofia, A., Esse'n, Anna Johnsson, Dan Bylund, Karsten Pedersen and Ulla, S. Lundstrom. 2007. Siderophore Production by Pseudomonas stutzeri under aerobic and anaerobic Conditions. Appl. Environ. Microbiol., 73: 58575864.

Sokol, P.A., C.J. Lewis and J.J. Dennis. 1992. Isolation of a novel siderophore from Pseudornonas cepacia. J. Med. Microbiol., 36: 184-189.

Sayyed, R.Z., M.D. Badgujar., H.M. Sonawane, M.M. Mhaske and S.B. Chincholkar. 2004. Production of microbial iron chilators (siderophores) by fluorescent pseudomonads. Indian $J$. Biotechnol., 4: 484-490.

\section{How to cite this article:}

Jayashri Pattan, Swapnil Kajale, Shashikant Pattan. 2017. Isolation, Production and Optimization of Siderophores (Iron Chilators) from Pseudomonas fluorescence NCIM 5096 and Pseudomonas from Soil Rhizosphere and Marine Water. Int.J.Curr.Microbiol.App.Sci. 6(3): 919-928. doi: https://doi.org/10.20546/ijcmas.2017.603.109 